\title{
DEMOCRATIZAÇÃO DO ACESSO E DO SUCESSO NO ENSINO SUPERIOR:UMA REFLEXÃO A PARTIR DAS REALIDADES DE PORTUGAL E DO BRASIL
}

\author{
LEANDRo AlmeidA* \\ Claisy Maria Marinho-Araujo** \\ Alberto Amaral*** \\ DiANA DiAS****
}

Recebido: 02 jan. 2012

Aprovado: 04 abr. 2012

\begin{abstract}
* Professor Catedrático do Instituto de Educação da Universidade do Minho. Braga, Portugal. E-mail: leandro@ie.uminho.pt

**Doutora, Bolsista Cnpq e Professora do Instituto de Psicologia da Universidade de Brasília. Brasília, DF, Brasil. E-mail: claisy@unb.br

***Doutor e Pesquisador do Centro de Investigação de Políticas do Ensino Superior (CIPES). Matosinhos, Portugal. E-mail: aamaral@cipes.up.pt

****Doutora e Pesquisadora do Laureate International Universities ISLA Campus Lx Lisboa e do Centro de Investigação de Políticas de Ensino Superior, Matosinhos. Porto, Portugal. E-mail: diana.dias@1x.isla.pt
\end{abstract}

Resumo: Associa-se frequentemente o termo "massificação" do ensino superior à democratização de seu acesso por parte de alunos provenientes das camadas sociais e culturais menos favorecidas e com menor tradição familiar de formação acadêmica superior. Neste artigo, pretende-se discutir, com base na análise de alguns indicadores da forte expansão ocorrida nos sistemas de ensino superior de Portugal e do Brasil nas últimas décadas, a efetiva democratização ocorrida. Vários pontos desse crescimento exponencial e alguns mecanismos de regulação criados, entretanto, permitem que se afirme que o ensino superior se abriu na realidade a estratos sociais e a públicos menos tradicionais neste nível de ensino; contudo, permanecem acentuadas assimetrias sociais nas instituições e nos cursos a que se tem acesso, ao mesmo tempo em que a permanência e abandono também se diferenciam socialmente em termos das respectivas taxas de incidência. Estes fenômenos têm causas diversas, não sendo possível ilibar as próprias instituições de ensino superior de responsabilidades nesse cenário.

Palavras-chave: Ensino Superior. Expansão. Massificação. Democratização. Portugal. Brasil.

\section{DEMOCRATIZATION OF ACCESS AND SUCCESS IN HIGHER EDUCATION: A REFLECTION FROM THE REALITIES OF PORTUGAL AND BRAZIL}

Abstract: The "massification" of higher education is associated to greater democratization of attendance by students from social and cultural backgrounds with fewer opportunities and less family tradition of academic education. In this article, we intend to discuss, based on the analysis of some indicators of strong growth that has occurred in higher education systems in Portugal and Brazil in recent decades, how the effective democratization occurred. Several points of this exponential growth and some regulatory mechanisms created, however, allow us to say that higher education was opened to the social strata and less traditional public education at this level, but social inequalities still remain high in institutions and programs, as can be observed by permanence and dropout rates. These phenomena have many causes, and can not acquit higher institutions from their share of responsibility for the problem.

Key words: Higher education. Expansion. Massification. Democratization. Portugal. Brazil. 


\section{INTRODUÇÃO}

Em uma conjuntura na qual a massificação do Ensino Superior é uma realidade incontornável, cumpre perceber até que ponto é que tal massificação decorre de uma efetiva democratização, tanto do acesso como do sucesso de parte dos grupos sócio-culturais menos favorecidos que freqüentam essa modalidade de ensino. Em relação ao acesso, o presente artigo pretende, através de uma breve análise da expansão do ensino superior em Portugal e no Brasil, apontar como o sistema político e as instituições de ensino superior (IES) nos dois países responderam à necessidade de maior número de quadros técnicos superiores por parte do mercado de trabalho e à maior procura da educação terciária por parte da população.

Atestando a relevância social e acadêmica do problema, o acesso ao ensino superior aparece regulado nos dois países pelo ratio de candidatos face ao número de vagas, havendo alguns sinais de que a pretensa democratização do acesso se encontra comprometida. Candidatos de grupos sociais mais desfavorecidos chegam em menor percentagem às instituições e aos cursos mais prestigiados socialmente, podendo a situação influenciar projetos vocacionais e de carreira profissional futura; por terem origem nos percursos escolares anteriores, algumas situações impactam as classificações que definem a candidatura dos estudantes ao ensino superior.

Se a democratização do acesso pode ser questionável, maiores reservas pode-se antecipar quando se analisa o sucesso acadêmico e a conclusão dos cursos. Vários estudos disponíveis apontam que as taxas de insucesso acadêmico e de abandono estão igualmente associadas à origem social dos estudantes (TAVARES, 2008). De uma forma geral, e mesmo não deixando de mencionar as variáveis mais diretamente relacionadas com os cursos e as instituições, a maioria da bibliografia existente focaliza com maior pormenor as variáveis pessoais do estudante, por exemplo, as suas estratégias de aprendizagem e os projetos de carreira.

Neste artigo, discutindo a democratização associada ao fenômeno da expansão do ensino superior em Portugal e no Brasil, procura-se alargar o leque de variáveis como forma de melhor responder à complexidade do problema. Assim, a par das variáveis pessoais do estudante, integram-se variáveis mais diretamente relacionadas com as próprias IES. Esta preocupação, assegurando uma compreensão mais abrangente dos fenômenos em análise, permite corresponsabilizar as IES pela maior ou menor democratização social conseguida em termos de acesso, sucesso e conclusão dos respectivos cursos. 


\section{EXPANSÃO E EQUIDADE DA EDUCAÇÃO SUPERIOR EM PORTUGAL}

Apesar de todos os esforços feitos na sequência do 25 de Abril, Portugal apresenta ainda indicadores educacionais extremamente preocupantes, nomeadamente quando comparados com outros países europeus.

Quando se deu a revolução de 1974, o ensino superior português era um sistema de elite, com uma taxa de participação muito baixa (da ordem dos 7\%), sendo os alunos majoritariamente recrutados nas classes sociais de maiores recursos. Após a revolução, verificou-se um grande aumento da procura pelo ensino superior, a que o governo respondeu com a criação de um sistema generalizado de numerus clausus, como forma de evitar uma ocupação excessiva das instituições de ensino superior públicas. Porém, esta medida veio criar pressões sociais crescentes por parte dos alunos que não conseguiam lugar no ensino superior, e de suas famílias. Estas pressões, conjugadas com o reconhecimento de que Portugal tinha de convergir para a Europa, forçaram um alargamento do sistema, que foi essencialmente conseguido por uma abertura do ensino superior ao setor privado e pela criação, na sequência de intervenções do Banco Mundial, de um setor público politécnico de ensino superior, mais curto e de caráter mais vocacional. Portugal fez, assim, um significativo esforço em termos de ampliação do acesso ao ensino superior, o que se traduziu numa taxa de acréscimo sem paralelo nos demais países europeus - cerca de 6\% para Portugal contra cerca de 3\% para a União Européia (EURYDICE, 2005).

Para o problema aqui em foco, importa analisar como foi feito este forte incremento da entrada ao ensino superior em Portugal. Assim, na década de 1990, houve um aumento de 105,8\% no número total de alunos, expansão não uniformemente distribuída pelo sistema. O número de alunos nas universidades públicas aumentou $62 \%$, enquanto o de alunos nos politécnicos públicos teve um incremento extraordinário de $224,7 \%$. Por sua vez, a quantidade de alunos no setor privado cresceu $121,7 \%$. Em termos de taxas brutas de participação no ensino superior (20-24 anos), a sua evolução ultrapassou os 50\% em 2001, o que representa um aumento extremamente rápido e sem paralelo em qualquer outro país europeu (OECD, 2005).

Mas, se inicialmente, o crescimento foi em grande parte devido ao aumento do setor privado (este registrou, em 1991, um crescimento anual de 33,5\%), esta expansão muito rápida começou a abrandar a partir do meio dos anos 1990, chegando a tornar-se negativa, para voltar a um ligeiro crescimento nos últimos anos (nomeadamente 2006/2007). Esta alteração na tendência de abran- 
damento da última década ficou a dever-se não só ao impacto da legislação, favorecendo o acesso de alunos maiores de 23 anos ao ensino superior (em 2007/2008, cerca de 14\% dos estudantes inscritos no Ensino Superior usaram esta forma de acesso), mas também à notória diminuição do insucesso verificada no Ensino Secundário (de 2000 a 2007 as taxas de insucesso no Ensino Secundário praticamente diminuíram para metade, passando respectivamente de $40 \%$ para 22\%) (ALMEIDA, 2002, 2007; ALMEIDA; VASCONCELOS, 2008; AMARAL; TEIXEIRA, 1999).

O crescimento dos institutos politécnicos públicos deu-se de uma forma mais sustentada e o número total dos seus alunos ultrapassou o do setor privado (desde 2001), mantendo-se esta tendência até hoje. O abrandamento no crescimento do número de alunos já foi observado também no caso das universidades públicas, com um primeiro valor negativo em 2003, embora a tendência seja para uma certa estabilidade na última década, conforme gráfico abaixo.

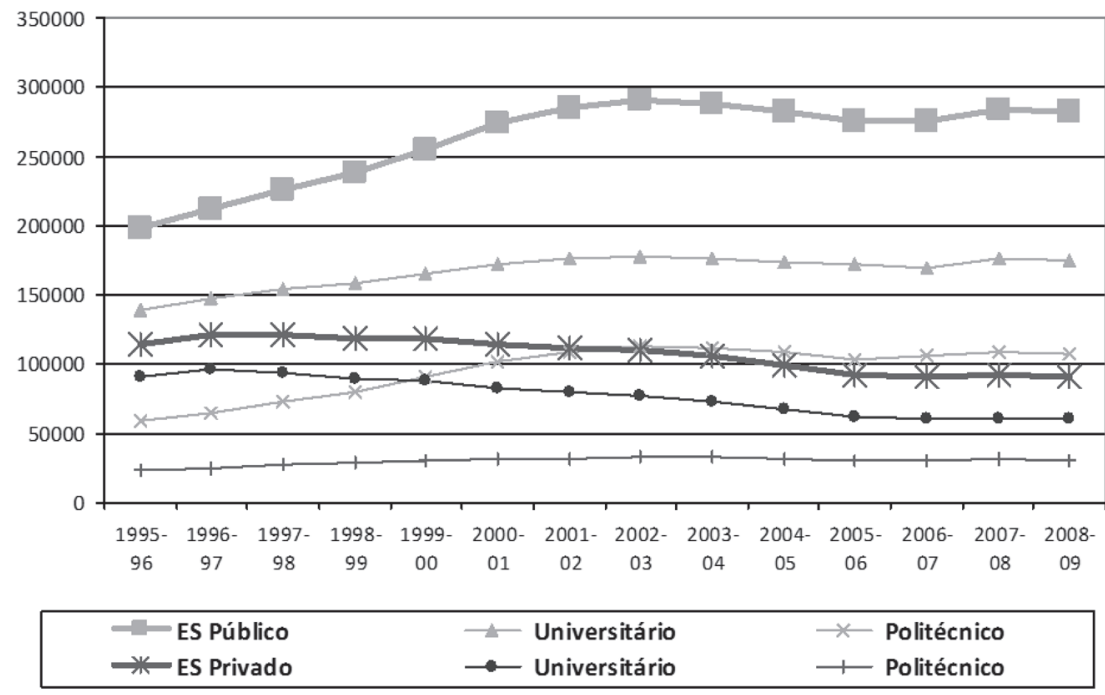

Fonte: Ministério da Ciência e da Tecnologia (MCTES/GPEARI, 2010). Portugal.

Este abrandamento, extensível aos vários subsistemas de ensino superior, decorre da diminuição da taxa de natalidade ocorrida nas duas últimas décadas em Portugal. Por este fato, existe hoje uma capacidade instalada excessiva para o número de candidatos ao ensino superior, o que forçará, no curto ou médio 
prazo, a uma racionalização/consolidação do sistema. Por outro lado, não se prevendo ocorrer nos próximos anos qualquer acréscimo no número de potenciais candidatos entre os "alunos tradicionais", a única forma de aumentar o número de alunos no ensino superior passará por um aumento significativo da eficiência dos subsistemas secundário e superior. Importa, pois, atenuar as taxas demasiado elevadas de saídas antecipadas e precoces do sistema educativo no final do ensino básico ou durante o ensino secundário, ao mesmo tempo em que o ensino superior deverá tomar medidas no sentido de aumentar o sucesso e prevenir as desistências entre os seus alunos.

Mas será que a expansão do ensino superior em Portugal se fez acompanhar por uma efetiva democratização ou equidade social deste nível de ensino? Infelizmente, a análise dos indicadores socioeconômicos mostra que a natureza da família dos alunos tem uma influência enorme no acesso ao ensino superior, pelo que Portugal está ainda longe de ter um sistema equitativo. A probabilidade de acesso por parte de um aluno de família de alto capital social e cultural é cerca de 10 vezes superior à de um aluno proveniente de família de mais baixos recursos (TAVARES, 2008). Entre os países europeus, Portugal é aquele com maior predomínio de alunos provenientes de famílias já com cursos superiores (HIS, 2005). Estatísticas recentes apontam que, na população portuguesa entre 40 e 60 anos, a taxa de diplomados com o ensino superior se situa em apenas $9,8 \%$, subindo para $35,8 \%$ quando se consideram os pais cujos filhos frequentam o ensino superior. Por outro lado, os detentores do nível educativo mais baixo atingem $62,5 \%$ da população portuguesa, descendo essa taxa para $22,0 \%$ quando nos reportamos aos pais cujos filhos frequentam o ensino superior. Neste sentido, existe uma sobre-representação de alunos provenientes de famílias com formação superior e uma sub-representação dos alunos de famílias com o nível educativo mais baixo (PORTUGAL, 2005).

Acresce, ainda, que a influência do capital social e cultural das famílias não se confina ao acesso no ensino superior. Segundo vários estudos nacionais, ela está igualmente presente na escolha do tipo de instituição e de curso por parte dos alunos (BALSA et al, 2001; CRUZ; CRUZEIRO, 1995; CABRITO, 2001; GAGO et al, 1994). Tomando outros dados (TAVARES et al, 2008), também se verifica que quanto maior é o capital social da família, maior é a tendência de escolha de cursos universitários mais longos e com maior relevo social, como por exemplo Medicina, Direito e Engenharia. No caso das famílias de menores recursos, é maior a procura de cursos mais curtos e mais dirigidos para o mercado de trabalho. Segundo Bourdieu (1989), embora os alunos sejam livres para escolher qualquer curso ou instituição, essas escolhas são 
feitas usando critérios aprendidos e influenciados pelo seu grupo social. Os alunos relacionam a escolha à acessibilidade a uma determinada profissão, com os obstáculos e oportunidades inerentes ao seu contexto social e cultural (GOTTFREDSON, 1981).

Os dados disponíveis sugerem, assim, que a massificação do sistema de ensino superior português não foi acompanhada de forma proporcional pela sua democratização, acrescentando-se que a expansão desse sistema ficou mais a dever-se à "feminização" do ensino superior, pelo ingresso crescente das alunas das famílias das classes média e alta, do que ao maior acesso dos alunos provenientes das famílias menos favorecidas.

No entanto, a leitura da maior ou menor equidade social do ensino superior em Portugal não se pode confinar ao acesso, sendo relevante considerar nesta análise o insucesso e o abandono dos alunos. Dados da OCDE (2005) relativos ao ano letivo de 2003-2004 apontam para uma taxa de sucesso de 66\% dos alunos do Ensino Superior, que se perfila ligeiramente abaixo da média (70\%) dos países membro da União Europeia. Tais números indicam, ainda, que os índices de sucesso escolar mais elevados foram observados nas áreas da Saúde e Serviços Sociais, tanto no público como no privado, e Formação de Professores, essencialmente no ensino não público. Contrariamente, os níveis mais baixos de sucesso escolar foram identificados nas áreas de Informática, Engenharias e Ciências.

\section{EXPANSÃO E EQUIDADE DA EDUCAÇÃO SUPERIOR NO BRASIL}

Na década de 1990, o Brasil apresentava em seu sistema de ensino superior um total de 922 Instituições de Educação Superior (IES), com 6.644 cursos e 1.868 .529 alunos matriculados. No ano 2000, o país apresentava um total de 1.180 IES, sendo 1.004 instituições privadas e 176 públicas. Em 2005, já eram 2.165 IES (89,3\% instituições privadas) que ofertavam 20.407 cursos de graduação presencial. Atualmente, de acordo o Censo da Educação Superior de 2009, divulgado pelo Ministério da Educação em 2011 (BRASIL, 2011), há um total de 2.314 IES, 28.966 cursos, 5.954.021 estudantes e 307.815 docentes. A oferta de cursos de graduação presencial e a distância está concentrada em instituições de caráter privado ${ }^{1}$ - 89,4\% de instituições privadas (2.069) e 10,6\%

1 As instituições privadas podem ser sem fins lucrativos, como é o caso das instituições comunitárias, confessionais e filantrópicas, e com fins lucrativos (particulares). 
de instituições públicas (BRASIL, 2011). Entretanto, o número de concluintes, divulgado no referido Censo, foi de 959.197.

Um dado que merece destaque é o acelerado aumento dos cursos de educação a distância (EaD): 30,4\% contra 12,5\% nos cursos presenciais. As matrículas nos cursos de $\mathrm{EaD}$, em 2009, atingiram 14,1\% do toal de matrículas na graduação (BRASIL, 2011).

Há, portanto, uma forte expansão do sistema de ensino superior do Brasil. Tal expansão é historicamente necessária, tendo em vista o imperativo de incremento da formação por parte da sua população (segundo relatório da OCDE de 2007, a percentagem de jovens entre 18 e 24 anos que no Brasil frequentam o ensino superior situa-se apenas em $13 \%$ face a $66 \%$ em Portugal ou a $90 \%$ no Japão). Contudo, importa analisar a natureza dessa expansão. Por exemplo, fica evidente que a expansão decorre de uma forte privatização da oferta disponível, representada por uma taxa do setor privado que atinge praticamente $90 \%$ das instituições de ensino superior. Esta privatização apresenta um volume preocupante, pois, na última década, o Brasil expressou um aumento nas matrículas em instituições privadas de mais de $13 \%$ e um aumento de mais de $15 \%$ na oferta de cursos oriundos dessas instituições (BRASIL, 2009).

Segundo alguns estudos (CARVALHO, 2007; DOURADO, 2008; NUNES, 2007), a grande expansão do ensino privado brasileiro ocorreu, fundamentalmente, por meio da ampliação do número e da capacidade dos estabelecimentos, de construção de prédios pela mesma instituição mantenedora e da ocupação dos recursos humanos em diversos períodos letivos. Houve uma acelerada e indiscriminada abertura de cursos e instituições em diversos estados e municípios brasileiros, sem os necessários processos de regulação e avaliação da qualidade.

Diversificação e diferenciação institucional foram a tônica de um processo que fez proliferarem instituições não-universitárias de caráter predominantemente privado.

Entretanto, apesar dessa massificação da educação superior, uma outra dimensão de análise merece ser considerada: as vagas ofertadas não são totalmente preenchidas. Sobram, na educação superior brasileira, cerca de $40 \%$ das vagas ofertadas, considerando todos os estados do país (BRASIL, 2009). Estas vagas encontram-se, quase totalmente, em instituições de ensino superior privadas e sugerem dificuldades econômicas dos estudantes para assumirem os custos das mensalidades. Com a crescente democratização da educação básica, jovens provenientes das baixas camadas socioeconômicas começam a chegar à educação superior; como as universidades públicas e gratuitas oferecem vagas em número insuficiente para atender a essa demanda, muitos ficam restringidos ao ensino 
superior privado. Com objetivo de atrair a população excedente das universidades públicas, e para desencorajar a instalação de instituições concorrentes, o setor privado tende a oferecer vagas em grandes quantidades, muitas vezes acima da previsão de preenchimento. Observa-se, não raro, também um total desequilíbrio na oferta formativa. Assim, assiste-se por vezes a um volume grande de oferta de vagas em cursos para os quais o ensino médio não ofereceu formação em uma dada região, muitas vagas disponíveis nos grandes centros urbanos dos principais estados e uma ausência em regiões de periferia, ou um grande volume de vagas em cursos específicos como Administração, Direito e Pedagogia.

Analisando os alunos que suportam esta expansão do ensino superior no Brasil, assiste-se a um novo perfil de estudante da educação superior. Pesquisas indicam que não é mais feita só de jovens entre 18 a 24 anos essa população. Segundo o Censo de 2009, relativo aos dados do perfil dos estudantes, há públicos diferenciados conforme a modalidade de ensino (BRASIL, 2011). Enquanto o estudante da graduação presencial tem, em média, 26 anos por ocasião da matrícula, o aluno da EaD ingressa na educação superior mais tardiamente, em torno dos 36 anos (BRASIL, 2011). Incentivados pela democratização do acesso, adultos já exercendo uma atividade profissional buscam a educação superior para obtenção de um diploma para qualificação e promoção profissional, muitas vezes concretizando projetos vocacionais que, pelo atraso escolar ou pela necessidade de rápida entrada ao mercado de trabalho, não puderam ocorrer em idade mais jovem.

Este perfil de estudante é considerado diferente do "aluno tradicional", que se apresenta na faixa etária esperada, tem bom background familiar, recursos financeiros, motivação e segurança na escolha profissional, e um histórico escolar de inclusão social e sucesso acadêmicos. Já o "aluno novo", especialmente no Brasil, escolhe e frequenta cursos noturnos de IES privadas, comumente de baixa seletividade e de rápida duração; utiliza parte do seu tempo para sua subsistência e/ou de sua família; é, geralmente, pertencente à primeira geração de longa escolaridade; não dispõe de tempo, espaço e condições apropriadas para estudar; teve e tem pouca aproximação com os artefatos intelectuais e artísticos da cultura hegemônica; tem muitas dificuldades para conciliar o tempo de trabalho com as atividades acadêmicas extra-aula (extensão cultural, pesquisa, encontros científicos); possui pouca motivação, recursos e disposição para relacionamentos, atividades sociais e culturais com outros estudantes (BRITTO et al, 2008; CARVALHO, 2007; NUNES, 2007).

A partir desse perfil, alguns autores (BORI; DURHAM, 2000; BOURDIEU; CHAMPAGNE, 2001; BRITTO et al, 2008; FREITAS, 2002; NU- 
NES, 2007; ZAGO, 2006) chamam a atenção para o fenômeno da "exclusão dos incluídos": o "aluno novo" consegue ter acesso ao ensino superior, mas tem inúmeras dificuldades para manter-se nesse segmento respondendo às expectativas de sucesso acadêmicos. Torna-se, simbolicamente, "excluído" após ter sido "incluído". Na esteira desses argumentos, pesquisas questionam, inclusive, a democratização no acesso visto que a escolha pelo curso, carreira ou profissão não é prerrogativa do estudante, sendo-lhe antes "circunstancializada" pelo seu perfil (ZAGO, 2006). Há, a despeito da massificação do ensino superior - ou em razão dela -, uma desigualdade de oportunidades ao acesso, construída histórica e socialmente: "Para a grande maioria não existe verdadeiramente uma escolha, mas uma adaptação, um ajuste às condições que o candidato julga condizentes com sua realidade e que representam menor risco de exclusão" (p. 9).

Em síntese, o fenômeno da expansão, democratização e massificação da educação superior no Brasil é expresso por dados quantitativos, indicadores ideológicos, imbricação entre política socioeconômica e educacional, desenhos curriculares ou perfil de estudante, aproximando a caracterização desse sistema muito mais das atividades empresariais do que acadêmicas (BITTAR; OLIVEIRA; MOROSINI, 2008; DIAS SOBRINHO, 2008; MOROSINI, 2003, 2006; MOROSINI; FRANCO, 2006). Assim, é no mínimo questionável se a expansão ocorrida no ensino superior se traduziu numa efetiva democratização do acesso, mais ainda quando se pretende estender essa democratização ao sucesso acadêmicos dos estudantes.

\section{INSUCESSO E ABANDONO NO ENSINO SUPERIOR}

Se a democratização do acesso é claramente posta em causa pelos dados anteriormente apresentados, quer no caso de Portugal, quer no caso do Brasil, importa estender a questão da democratização do ensino superior à sua frequencia, sucesso acadêmicos e conclusão dos cursos por parte dos alunos. Aqui, a pesquisa volta-se, sobretudo, para as variáveis pessoais do aluno, em particular quando se procura explicar o fenômeno do insucesso e do abandono. Contudo, nesta análise, importa igualmente considerar variáveis associadas à instituição de ensino, incluindo aqui logicamente o curso e o currículo acadêmicos frequentado.

Autores defendem que a aprendizagem discente é mais determinada por aquilo que o aluno sabe e faz, do que por aquilo que faz o professor (ALMEIDA, 2002, 2007; BIGGS, 1987; ROSÁRIO et al, 2000). Assim, vários fatores 
ao nível do aluno podem ser apontados na explicação das suas dificuldades de aprendizagem e de realização acadêmica no ensino superior, extrapolando-se, também, para as situações de abandono: indecisão vocacional, desmotivação, baixa capacidade, falta de bases de conhecimentos, métodos de trabalho pouco apropriados, abordagens inadequadas ao estudo e à aprendizagem. Face a um ensino menos formalizado em termos de manuais, de turmas e de contacto assíduo com os docentes, é importante a autoregulação do aluno, a sua motivação, a organização, a auto-disciplina e a persistência no trabalho escolar (ALMEIDA, 2007; CHAMORRO-PREMUZIC; FURNHAM, 2008; O'CONNOR; PAUNONEN, 2007). Algo do insucesso acadêmico decorre da falta de correspondência entre as necessidades, os interesses e os valores dos alunos e as expectativas da sua concretização no quadro de determinado curso, bem como dos tipos de "respostas" disponibilizadas pela instituição, numa lógica de "desenvolvimento de carreira".

Os alunos do $1^{\circ}$ ano têm sido alvo de grande interesse pela comunidade científica, na medida em que podem ser considerados um grupo de "risco", parecendo ser maior esse risco quando frequentam cursos nas áreas das ciências e engenharias (TAVARES, 2008; SOARES, 2003; SOARES et al, 2009; TAVARES; SANTIAGO; LENCASTRE, 1998; VASCONCELOS; ALMEIDA; MONTEIRO, 2005). Na verdade, trata-se de um momento de transição extremamente desafiante que implica um conjunto de adaptações significativamente alargadas e complexas e que abrangem as mais diversas áreas de desenvolvimento (pessoal, social, vocacional, relacional etc.). Neste contexto de mudança, as expectativas que o novo aluno traz consigo, e que decorrem de todo o percurso desenvolvimental que o levou até ao Ensino Superior, assumem maior importância. Tais expectativas estão relacionadas com aspirações passadas e atuais, com investimentos e projetos profissionais futuros, mobilizando os estudantes, de forma e intensidade diversas, para a aprendizagem e a realização acadêmica (ALMEIDA, 2007; ALMEIDA et al, 2006; SOARES, 2003; TAVEIRA, 2000). Diversos estudos demonstram que alunos com altas expectativas apresentam uma maior probabilidade de se graduarem ( $56.5 \%$ versus $40.3 \%$ ) e uma menor probabilidade de desistirem por insucesso ( $7.1 \%$ versus $25 \%$ ), comparados com alunos com baixas expectativas (ALMEIDA, 2007; ALMEIDA et al, 2006; SOARES, 2003; TAVEIRA, 2000).

Investigações levadas a cabo no Brasil e em Portugal concordam quanto à complexidade e variedade de desafios e pressões que se apresentam aos novos alunos e para os quais nem sempre estão preparados (TAVARES et al, 2008; BRITTO et al, 2008; CARVALHO, 2007; NUNES, 2007; SOARES; GUISAN- 
DE; ALMEIDA, 2007; ZAGO, 2006). Os professores mantêm a expectativa de alunos devidamente preparados, motivados e com total "prontidão" para aproveitarem a "chance" que tiveram de aceder ao curso. A transição para o ensino superior acarreta, para vários deles, dificuldades quotidianas não vivenciadas anteriormente como procura de moradia, transporte e alimentação. Da mesma forma, o estudante é forçado ao estabelecimento de novas relações sociais e a encontrar grupos de suporte afetivo e social no novo contexto de vida. Tudo isto se pode agravar, ainda, se o estudante precisa, desde o início, encontrar vias de financiamento dos seus estudos como forma de não ter que adiar a sua formação.

O insucesso acadêmico dos estudantes passa também pelo professor, pelo curso, pela estrutura curricular do curso e pela instituição e seus serviços. As práticas pedagógicas, o currículo e a avaliação influenciam as taxas de sucesso dos estudantes. Subjacente a este pressuposto está a transição de um modelo pedagógico tradicional baseado em aulas magistrais para um processo de ensino-aprendizagem centrado no aluno, no qual se valoriza a aprendizagem ativa (ALMEIDA, 2007; ALMEIDA; VASCONCELOS, 2008; BROWN; PENDLEBURY, 1992), o que tem sido ainda mais propagado com a Declaração de Bolonha. Simão e Flores (2006) apontam, neste contexto, para a reconceitualização da docência universitária. Neste âmbito, como referem os autores, o modelo transmissivo não permite responder à complexidade atual, sendo necessárias, para além do conhecimento aprofundado da área de especialização e das competências de investigação, dimensões muito mais amplas, implicando, nomeadamente, conhecimentos nas áreas da psicologia e da pedagogia. Ilustrando, tais conhecimentos repartem-se pela área do currículo, avaliação, teorias da aprendizagem, desenvolvimento e aprendizagem do adulto, organização da instituição, métodos de ensino e estratégias de aprendizagem ou relação pedagógica, entre outras.

As questões do acesso ao ensino superior são também relevantes para o debate sobre o insucesso e o abandono acadêmicos. A par da crescente massificação do ensino superior, importa reter que uma percentagem considerável de estudantes verbaliza não entrar num curso de formação correspondente às suas primeiras opções vocacionais. Sendo certo que nem sempre as primeiras opções são tão convictamente assumidas, ou acreditando-se que ao longo do tempo os alunos podem mudar os seus projetos de carreira e até virem a investir nos cursos que frequentam em segunda ou terceira escolha, a política instituída de "numerus clausus" merece contínua análise nos seus efeitos. Importa repensar, por exemplo, o tipo de oferta formativa, a relação oferta-procura ou 
a emergência de novos públicos e novos perfis de competências (CIPES, 2008; SANTOS, 2000).

Neste quadro mais amplo de análise, Tinto (1993) defende que os jovens que decidem entrar no ensino superior acumulam em si próprios um conjunto de atributos (a que se poderá chamar atributos pré-universitários) que incluem o seu background familiar (por exemplo, o nível socioeconômico e cultural dos pais), características individuais (por exemplo, o gênero e a etnia), competências (por exemplo sociais, éticas, físicas e intelectuais), recursos financeiros e disposições, como as suas motivações, expectativas e preferências intelectuais, sociais e políticas, e também características do seu percurso escolar anterior, como as médias obtidas nos exames, as bases de conhecimentos ou os hábitos de estudo. Cada um destes atributos tem impacto no sucesso acadêmicos, assim como na decisão de abandono acadêmicos dos jovens alunos. Com efeito, afetando diretamente a sua aprendizagem e rendimento acadêmicos, tais variáveis condicionam as intenções de permanecer e concluir a formação.

Contudo, chegados ao ensino superior, esses mesmos atributos do aluno interagem com um conjunto mais alargado de variáveis inerentes ao curso, ao ensino e à instituição. Vallerand, Fortier e Guay (1997) verificaram que os alunos que abandonam o seu percurso formativo apresentam níveis mais baixos de identificação acadêmica e de suporte por parte dos professores, pais e gestores acadêmicos. Por sua vez, Cabrera et al (1992) destacam que as crenças, atitudes e condutas dos estudantes são influenciadas por uma série de fatores, a nível acadêmico, pessoal e social, internos e externos à comunidade acadêmica envolvente. Concretamente, esses fatores podem ser, por exemplo, os serviços e os recursos que a instituição disponibiliza, o interesse pelo curso frequentado, a influência do grupo de pares ou de pessoas significativas fora do contexto universitário. Em particular, os autores destacam o encorajamento familiar à frequencia do ensino superior, as atitudes face a aspectos financeiros inerentes à frequencia e à conclusão do curso e, ainda, aspectos associados às facilidades oferecidas pelo sistema de ensino e pelo mundo de trabalho (ALMEIDA; VASCONCELOS; MENDES, 2008).

Assim sendo, na explicação do abandono, este processo implica não só as características dos estudantes e as características e exigências colocadas pela instituição universitária, como também as pressões exercidas por esses fatores externos (como a família, os grupos de amigos, organizações da comunidade ou empregadores). O impacto exercido por estas 
pressões depende, em grande escala, do relacionamento interpessoal que o estudante possa desenvolver com entidades da comunidade acadêmica, do nível de maturidade e autonomia atingido, e das expectativas e projetos de carreira profissional que interliga com a sua formação. Considerando todos estes processos, caberá ao estudante conseguir equilibrar e corresponder adequadamente às pressões, internas e externas, de que é alvo (ALMEIDA; VASCONCELOS; MENDES, 2008; SOARES, 2003).

Em síntese, ilustrou-se um conjunto de fatores que se interpenetram na explicação do sucesso no Ensino Superior. Importa, de novo, recolocar a questão da origem social do aluno e seu impacto no problema em análise. Se nas variáveis pessoais do aluno, desde os recursos que possui, seu background acadêmico, sua motivação, escolha ou não como primeira opção do curso que frequenta, expectativa de carreira, facilmente é possível reconhecer o peso de tais variáveis sócioculturais, importa verificar em que medida as praxis institucionais (currículo, relação com docentes, recursos...) não acabam por ter maior impacto no insucesso e abandono junto dos alunos menos favorecidos em termos sociais. Por exemplo, as dificuldades na transição e adaptação acadêmica podem ser bem menores por parte dos alunos habituados a conviver com pessoas que frequentaram o ensino superior. Da mesma forma, a falta de equipamento ou de bibliografia pode ter um impacto diferenciado num aluno com recursos econômicos familiares para os adquirir relativamente a um aluno sem esses recursos familiares. Esta situação generaliza-se a muitos outros aspectos mencionados ao longo deste artigo. Assim sendo, e na tentativa de aumentar a democratização do sucesso no Ensino Superior, importa apontar algumas medidas institucionais e sociais de atenção a estes alunos de forma a tornar mais efetiva a democratização do ensino superior.

\section{CONSIDERAÇÕES FINAIS E PERSPECTIVAS DE INTERVENÇÃO}

Nos países em desenvolvimento tem-se verificado um aumento exponencial de ingressos no Ensino Superior. Nestes países, a Universidade exclusiva de "elites sociais e culturais" desapareceu face à necessidade de incremento significativo do número de técnicos altamente qualificados por parte do mercado de trabalho. A vida social também se complexificou bastante, exigindo novas políticas em que a inclusão e a democratização se assumem como valores a 
prosseguir numa sociedade cada vez mais diversa e diferenciada. Neste sentido, as instituições de ensino superior passaram a ser procuradas e frequentadas por um número crescente de alunos, o que se traduziu num fenômeno de massificação do Ensino Superior ao nível da sua população discente. Este crescendo verificou-se, ainda, no surgimento de muitas instituições públicas e privadas, assim como na criação de um número elevado e diverso de cursos.

Uma forma de entender esta massificação pela positiva é pensá-la como associada à necessidade de uma maior democratização do acesso dos alunos ao ensino superior. Com efeito, analisando a população discente facilmente verifica-se uma heterogeneidade crescente dos estudantes em termos das suas origens sociais e culturais. Lógico que uma análise mais precisa de tal heterogeneidade facilmente permite identificar algumas tensões que questionam essa pretensa democratização no acesso. Assim, em Portugal, a prática de numerus clausus faz com que nem todos os alunos acedam ao par estabelecimento/curso correspondente às suas primeiras escolhas vocacionais ou simples preferência. Sendo essa colocação feita na base de uma nota de candidatura que decorre em boa medida das classificações obtidas ao longo do Ensino Secundário, logo pode-se pensar que certas variáveis e condições sociais estão associadas a tais classificações. A qualidade das escolas frequentadas, os apoios recebidos, o background acadêmicos e cultural estão fortemente marcados pelas variáveis sociais de pertença e é certo que condicionam a nota de candidatura com que os alunos acedem ao ensino superior. Por sua vez, os cursos de maior prestígio social aparecem como primeiras escolhas dos alunos, assim como a opção pelo ensino universitário face ao ensino politécnico ou por determinadas instituições em comparação a outras, e apenas os alunos com melhores notas de candidatura podem frequentar os pares cursos/instituições correspondentes às suas primeiras escolhas. Ao mesmo tempo, e na situação de maiores dificuldades econômicas por parte das famílias, as escolhas dos jovens podem ficar bastante condicionadas às ofertas formativas nas instituições geograficamente mais próximas, evitando-se, assim, grandes encargos econômicos com a deslocação e a estadia dos alunos fora da família.

Por sua vez no Brasil, a expansão registrada no ensino superior foi feita essencialmente à custa de um aumento exponencial de instituições do setor privado, também traduzido pela multiplicação de cursos e do número de ingressos disponíveis por parte destas instituições. Constrangidos por um setor público de ensino, gratuito, que não oferece um número de vagas capaz de responder minimamente à demanda social existente de formação superior, mais de dois terços dos estudantes frequentam o seu curso no ensino superior privado. Geral- 
mente em função de dificuldades financeiras para suportarem a sua formação, alguns jovens protelam o ingresso no ensino superior para idades posteriores e após entrarem no mundo de trabalho.

Se a democratização do acesso em termos de equidade social suscita já sérias dúvidas e reservas, o problema ganha contornos mais evidentes quando se analisa a democratização do sucesso. Nesta altura, as taxas de abandono e de insucesso penalizam, sobretudo, os alunos provenientes dos estratos sociais mais desfavorecidos, mesmo não havendo estatísticas seguras para o demonstrar. De novo, a frequencia a um curso de que não se gosta e a necessidade de conciliar os estudos com alguma forma de trabalho, mesmo que temporário (quando, por exemplo em Portugal, os horários de funcionamento das aulas são essencialmente diurnos) são fatores explicativos de uma taxa considerável de insucesso e de abandono, sobretudo junto dos alunos pertencentes aos grupos sociais mais desfavorecidos.

A academia não pode uniformizar as suas práticas e regulamentos, inclusive os seus horários e procedimentos de acesso aos seus recursos, se pretende responder à heterogeneidade de alunos que hoje acolhe. A falta de horários póslaborais, por exemplo, leva a que alguns alunos abandonem o Ensino Superior quando necessitam de uma atividade profissional para custear os seus estudos. A questão dos horários é recorrente, por exemplo, no discurso dos alunos que abandonaram a Universidade do Minho, em Portugal (ALMEIDA; VASCONCELOS; MENDES, 2008). Quando se assiste a um aumento dos chamados "alunos não tradicionais" (alunos maiores de 25 anos, com compromissos familiares e de emprego), mais sentido faz uma abertura do campus à noite e ao fim-de-semana, prática esta que ainda não é frequente nas universidades públicas em Portugal, muito embora tenha já alguma expressão no setor privado. Já no Brasil esta problemática tem tido resposta essencialmente pelas IES privadas, cuja oferta ocorre precisamente em horários pós-laborais (de acrescentar que o setor privado de ensino superior no Brasil ultrapassa os $80 \%$ da oferta, não chegando em Portugal a metade desse valor).

A Educação Superior pode ser entendida, como o foram as escolas básica e secundária há algumas décadas atrás: como instituição de promoção social das famílias e grupos menos favorecidos. No cumprimento desta missão, a Educação Superior deve assegurar alguns serviços técnicos de apoio aos alunos que possam estar mais fragilizados para responder às exigências e desafios desta nova etapa formativa. Tais serviços podem contemplar um conjunto mais ou menos alargado de apoios, desde o apoio médico e social mais frequente, até o apoio psicológico e educativo mais recente. Estes serviços estão hoje 
bastante divulgados e frequentes em Portugal, atuando conforme a sua natureza e objetivos de criação, seja na adaptação ao curso seja na transição da Educação Superior para o mundo de trabalho. Assim, a par da tradição do apoio social através de bolsas, alojamentos e pequenas experiências de trabalho no campus (part-time), as instituições tomam hoje bastante em atenção o apoio vocacional aos alunos em função da sua menor clareza nas decisões vocacionais, competências de empregabilidade e gestão das carreiras. Na verdade, as instituições de Ensino Superior encerram em si mesmas competências que lhes permitem refletir e intervir ativamente na sua organização (seja ela, curricular, organizacional ou mesmo axiológica), com vista a criar e incrementar condições para que os primeiros momentos dos seus novos alunos possam ser vividos em um clima de maior receptividade, confiança e segurança, tentando controlar e equilibrar situações potencialmente geradoras de desconforto. Não se pretende, contudo, uma atitude de "maternage" abrangente e redutora de todas e quaisquer dificuldades inerentes ao processo de transição. Os problemas e os desafios são necessários, porque se assumem como potencializadores de um adequado desenvolvimento pessoal, daí a importância de um justo equilíbrio entre o apoio e o desafio que ajuda o "calouro" na sua gestão de tensões com que se vê confrontado, sem contudo the retirar a responsabilidade pelas suas opções de vida.

Sendo importante a transição, e sendo certo que muitos alunos das classes sociais mais desfavorecidas não possuem na família referências de frequencia do Ensino Superior, importa cuidar das práticas de acolhimento instituídas ou que faltam instituir. As praxes (em Portugal) ou os "trotes" (no Brasil) organizados no seio de grupos estudantis, ainda que com objetivos efetivos de facilitar a integração do novo estudante, podem mais agravar as dificuldades que facilitar a integração; por sua vez, a ausência de diretrizes concretas por parte dos professores e dos diretores dos cursos sobre a organização do plano curricular ou sobre as metodologias de ensino e aprendizagem deixam os alunos com menor background acadêmicos com sérias dificuldades em organizar e regular os seus hábitos de trabalho. Sendo certo que uma maior taxa de insucessos ocorre em alunos de primeiro ano, e em cursos de ciências e de engenharia, importa verificar como é feito o acolhimento nestes cursos, como é apresentada e justificada a estrutura do currículo. Muitas vezes, os primeiros semestres são preenchidos com disciplinas básicas ou propedêuticas (física, matemática, química) que os alunos têm dificuldade em perceber porque essas são tão fundamentais no seu curso, com consequencias óbvias na diminuição da sua motivação. Sobretudo, importa reconhecer que, aquilo que é óbvio para os professores pode não ser 
óbvio para os alunos, podendo os alunos provenientes de grupos sociais mais desfavorecidos apresentar uma décalage maior em tais percepções.

Um dos obstáculos apontados pelos alunos de baixos recursos econômicos são as suas dificuldades financeiras para realizar um conjunto de atividades quotidianas, por exemplo, acompanhar os colegas em algumas atividades sociais. A par da política de bolsas e do incremento de empréstimos bancários (prática ainda incipiente em Portugal), interessaria o desenvolvimento dos estudantes em atividades no campus, em programas de voluntariado ou a sua participação em projetos de pesquisa dos docentes, assegurando parte dos recursos necessários à satisfação de tais necessidades. No discurso de alunos que abandonaram a Educação Superior aparecem muitas vezes as necessidades de sustento pessoal ou de familiares, sendo que as atividades laborais daí decorrentes, muitas vezes, não conseguem compatibilizar com a continuidade dos estudos (ALMEIDA; VASCONCELOS; MENDES, 2008). De referir a possibilidade em Portugal dos estudantes-trabalhadores poderem beneficiar do estatuto de "estudante a tempo parcial", situação que permite atenuar este problema. Mesmo assim, estando as aulas, os laboratórios e os recursos confinados a um horário normal diurno, parte importante das dificuldades subsistem.

A terminar, analisando o binômio "massificação-democratização" do ensino superior no Brasil e em Portugal, entende-se que a expansão foi necessária, mas não é suficiente para garantir a democratização desejada. Há que se prever mudanças estruturais e funcionais, visando garantir um processo de expansão da educação superior com qualidade e equidade social. É então essencial (re) discutir a função social da educação superior, de forma pragmática e objetivando transformações. A um nível mais macro de atuação, por exemplo, interessa promover o normal fluxo das pessoas ao longo do ciclo de escolaridade (básico, secundário, superior) e de formação contínua, incrementar políticas de subsídios e bolsas aos estudantes em função dos seus projetos e necessidades familiares, regular a oferta formativa ao nível das instituições e cursos, qualificar os recursos humanos e materiais das instituições e articular a oferta de formação com as necessidades das pessoas, do mercado de trabalho e da sociedade em geral. 


\section{REFERÊNCIAS}

ALMEIDA, Leandro et al. Acesso e sucesso no ensino superior em Portugal: questões de género, origem sócio-cultural e percurso acadêmicos dos alunos. Psicologia: Reflexão e Crítica, Porto Alegre, n. 19, p. 507-514, 2006.

ALMEIDA, Leandro Silva. Sucesso e insucesso no ensino superior português. SEMINÁRIO SUCESSO E INSUCESSO NO ENSINO SUPERIOR PORTUGUÊS, Lisboa, 2002. Actas... Lisboa: Conselho Nacional de Educação, 2002. p. 103-119.

ALMEIDA, Leandro Silva. Transição, adaptação acadêmica e êxito escolar no ensino superior. Revista Galego-Portuguesa de Psicoloxía e Educación, Coruña, Espanha, v. 14, n. 2, p. 203-215, 2007.

ALMEIDA, Leandro Silva; VASCONCELOS, Rosa. Ensino superior em Portugal: décadas de profundas exigências e transformações. Innovación Educativa, México, n. 18, p. 23-34, 2008.

ALMEIDA, Leandro Silva; VASCONCELOS, Rosa; MENDES, Tatiana. O abandono dos estudantes no ensino superior: um estudo na Universidade do Minho. Revista Galego-Portuguesa de Psicoloxía e Educación, Coruña, Espanha, v. 16, n. 1,2, p. 109-117, 2008.

AMARAL, Alberto; TEIXEIRA, Pedro. Relatório da evolução do acesso ao ensino superior. Matosinhos: Centro de Investigação de Políticas do Ensino Superior (CIPES), Porto, 1999.

BALSA, Casimiro et al. Perfil dos estudantes do ensino superior: desigualdades e diferenciação. Lisboa: CEOS; Edições Colibri, 2001.

BIGGS, John. Student approaches to learning and studying. Hawthorn: Australian Council for Educational Research, 1987.

BITTAR, Mariluce; OLIVEIRA, João Ferreira; MOROSINI, Marília Costa. (Orgs.). Educação superior no Brasil - 10 anos pós-LDB. Brasília: INEP, 2008. v. 2. p. 348

BORI, Carolina M.; DURHAM, Eunice R. Equidade e heterogeneidade no ensino superior brasileiro. Brasília: INEP, 2000. 
BOURDIEU, Pierre. La noblesse D'État : grandes écoles et esprit de corps. Paris: Les Éditions de Minuit, 1989.

BOURDIEU, Pierre; CHAMPAGNE, Patrick. Os excluídos do interior. In: BOURDIEU, P. (Ed.). Escritos de educação. 3. ed. Petrópolis: Vozes, 2001.

BRITTO, Luiz Percival Leme et al. Conhecimento e formação nas IES periféricas perfil do aluno "novo" da educação superior. Avaliação, Campinas; Sorocaba, v. 13, n. 3, p. 777-791, nov. 2008.

BROWN, G.; PENDLEBURY, M.. Assessing active learning. Effective learning and teaching in higher education module 11. P. Cryer. Sheffield, CVCP Universities' Staff Development and Training Unit., 1992. Part 1, p. $79-82$

CABRERA, Alberto F. et al. The convergence between two theories of college persistence. Journal of Higher Education, Thousand Oaks, CA, USA, n. 63, p. 143-164, 1992.

CABRITO, B. G. Universidade e reprodução sócio-cultural. Revista de Educação, São Paulo, v. 10, n. 2, p. 25-37, 2001.

CARVALHO, Cristina Helena Almeida. Estudo comparado sobre a expansão do ensino superior: Brasil e Estados Unidos. In: ESCENARIOS MUNDIALES DE LA EDUCACIÓN SUPERIOR. Análisis global y estudios de casos. Buenos Aires: CLACSO (Consejo Latinoamericano de Ciencias Sociales), 2007.

CENTRO DE INVESTIGAÇÃO DE POLÍTICAS DO ENSINO SUPERIOR - CIPES. A rede pública de ensino superior: um olhar sobre o acesso. Porto: Cipes, 2008.

CHAMORRO-PREMUZIC, Tomas; FURNHAM, Adrian. Personality, intelligence and approaches to learning as predictors of academic performance. Educational Psychology, Memphis, TN, n. 26, 769-779, 2008 .

CRUZ, Manuel Braga da; CRUZEIRO, Maria Eduarda (Coords.). O desenvolvimento do ensino superior em Portugal. Situação e problemas de acesso, estudo realizado pelo ICS, Lisboa: Ministério da Educação DEPGEF, 1995. 
DIAS SOBRINHO, José. Avaliação educativa: produção de sentidos com valor de formação. Avaliação, Campinas; Sorocaba, v. 13, n. 1, p. 193-207, mar. 2008.

DOURADO, Luiz Fernandes. Políticas e gestão da educação superior: múltiplas regulações e reforma universitária no Brasil. In: SEMINÁRIO REDESTRADO - NUEVAS REGULACIONES EN AMÉRICA LATINA. 7. Buenos Aires. Anais.... Buenos Aires, 2008.

EURYDICE. Key data on education in Europe 2005. Luxembourg: Office for Official Publications of the European Communities, 2005.

FREITAS, Luiz Carlos. A internalização da exclusão. Educação e Sociedade, Campinas, v. 23, n. 80, p. 299-325, 2002.

GAGO, J. M. et al. Prospectiva do ensino superior em Portugal. Lisboa: Departamento de Programação e Gestão Financeira, Ministério da Educação, 1994.

GOTTFREDSON, Linda S. Circumscription and compromise: A developmental theory of occupational aspirations. Journal of Counseling Psychology, Washington, DC, v. 28, n. 6, p. 545-579, Nov. 1981.

HIS. Eurostudent Report - Social and economic conditions of student life in Europe. Hannover: HIS, 2005. Disponível em: $<$ http://bibliotecavirtual. CLACSO.org.ar/ar/libros/campus/segrera/06AdeCarvalho.pdf $>$. Acesso em: dez. 2009.

PORTUGAL. Ministério da Ciência e da Tecnologia - DGES/CIES. Condições socioeconómicas dos estudantes do ensino superior em Portugal. Lisboa: DGES/MCTES, 2005.

PORTUGAL. Ministério da Ciência e da Tecnologia (MCTES) - Gabinete de Planeamento, Estratégia, Avaliação e Relações Internacionais (GPEARI). Inovação e ensino superior, 2010. Retrieved March 10, 2010 from <http://www.gpeari. mctes.pt/?idc $=103>$

BRASIL. Ministério da Educação (MEC). Instituto Nacional de Estudos e Pesquisas Educacionais Anísio Teixeira (INEP). Resumo Técnico: Censo da Educação Superior 2009. Brasília: INEP, 2010. Disponível em: $<$ http://www. inep.gov.br> Acesso em: 10 dez. 2011. 
BRASIL. Ministério da Educação (MEC). Instituto Nacional de Estudos e Pesquisas Educacionais Anísio Teixeira (INEP). Resumo Técnico: Censo da Educação Superior 2008. Brasília: INEP, 2009. Disponível em: $<$ http://www. inep.gov.br> Acesso em: 10 fev. 2010.

MOROSINI, Marília Costa. (Org.). Enciclopédia de pedagogia universitária. Porto Alegre: FAPERGS/RIES, 2003.

MOROSINI, Marília Costa. (Org.). Universidade no Brasil: concepções e modelos. Brasília: Ed. Brasilia; INEP, 2006.

MOROSINI, Marília Costa; FRANCO, M. E. D. P. Escola de engenharia de Porto Alegre (1896-1934): hegemonia política na construção da universidade. História da Educação, Santa Maria, n. 19, p. 39-59, 2006.

NUNES, Edson. Desafio estratégico da política pública: o ensino superior brasileiro. Revista Administração Pública, Rio de Janeiro, n. 41, p. 103-147, 2007.

O'CONNOR, Melissa; PAUNONEN, Sampo. Big five personality predictors of post-secondary academic performance. Personality and individual differences, Washington, DC, v. 43, p. 971-990, 2007.

OECD. Education at a Glance. Paris: OECD, 2005.

ROSÁRIO, Pedro et al. As abordagens dos alunos à aprendizagem em função da área acadêmica: uma investigação na Universidade do Minho. In: SOARES, A. P. et al. Transição para o ensino superior. Braga: Universidade do Minho, 2000.

SANTOS, Sergio Machado dos. As responsabilidades da universidade no acesso ao ensino superior. In: SOARES, A. P. et al (Eds.). Transição para o ensino superior. Universidade do Minho: Conselho Acadêmicos, 2000.

SIMÃO, Ana Margarida Veiga; FLORES, Maria Assunção. O aluno universitário: aprender a auto-regular a aprendizagem sustentada por dispositivos participativos. Ciências \& Letras, Porto Alegre, n. 40, p. 229$251,2006$.

SOARES, Ana Paula et al. Academic achievement in first-year Portuguese college students: The role of academic preparation and learning strategies. International Journal of Psychology, Montreal, Canada, n. 44, p. 204-212, 2009. 
SOARES, Ana Paula. Transição e adaptação ao ensino superior: construção e validação de um modelo multidimensional de ajustamento de jovens ao contexto universitário. Tese (Doutorado). Instituto de Educação e Psicologia, Universidade do Minho, Braga, 2003.

SOARES, Ana Paula; GUISANDE, M. Adelina; ALMEIDA, Leandro Silva. Autonomía y ajuste acadêmicos: Un estudio con estudiantes portugueses de primer año. International Journal of Clinical and Health Psychology, Granada, Espanha, n. 7, p. 753-765, 2007.

TAVARES, Diana Amado et al. Student's preferences and needs in portuguese higher education. European Journal of Education, New York, v. 43, n. 1, p. 107-122, 2008.

TAVARES, Diana Amado. O superior ofício de ser aluno: manual de sobrevivência para caloiros. Lisboa: Sílabo, 2008.

TAVARES, José; SANTIAGO, Rui A.; LENCASTRE, Leonor. Insucesso no primeiro ano do ensino superior: um estudo no âmbito dos cursos de licenciatura em ciências e engenharia na Universidade de Aveiro. Aveiro: Universidade de Aveiro, 1998.

TAVEIRA, Maria do Céu. Sucesso no ensino superior: uma questão de adaptação e de desenvolvimento vocacional. In: TAVARES, J.; SANTIAGO, R. (Orgs.). Ensino superior: (In)sucesso acadêmico. Porto: Porto, 2000.

TINTO, Vincent. Leaving college: rethinking the causes and cures of student attrition. Chicago: University of Chicago Press, 1993.

VALLERAND, Robert. J.; FORTIER, M. S.; GUAY, Frédéric. Selfdetermination and persistence in a real-life setting: toward a motivational model of high school dropout. Journal of Personality and Social Psychology, Washington, DC, v. 72, n. 5, p.1161-1176, 1997.

VASCONCELOS, Rosa Maria; ALMEIDA, Leandro Silva; MONTEIRO, Sivia Correia. Métodos de estudo em alunos do $1^{\circ}$ ano da Universidade. Psicologia Escolar e Educacional, Maringá, n. 9, p. 195-202, 2005.

ZAGO, Nadir. Del acceso a la permanencia en la enseñanza superior: trayectos de estudiantes universitarios de clases sociales populares. Revista Brasileira de Educação, Rio de Janeiro, v. 11, n. 32, p. 226-237, 2006. 